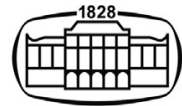

AKADÉMIAI KIADÓ

\title{
Application of chitosan as a natural disinfectant against porcine epidemic diarrhoea virus
}

\section{Acta Veterinaria Hungarica}

69 (2021) 1, 94-99

\section{DOI:}

10.1556/004.2021.00001

(c) 2021 The Author(s)

\section{ORIGINAL RESEARCH} PAPER

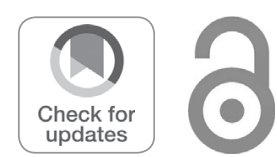

†These authors contributed equally to this work

*Corresponding authors. Tel.: +822 880 1255; fax: +82 28850263 .

E-mail: parkx026@snu.ac.kr; heeskyi@ snu.ac.kr

${ }^{* *}$ Corresponding author.

E-mail: yhp@snu.ac.kr

\section{AKJournals}

\author{
SUNG JAE $\mathrm{KIM}^{1 \dagger}$, VAN GIAP NGUYEN ${ }^{2 \dagger}$, \\ CHEONG UNG KIM ${ }^{3 \dagger}$, BONG KYUN PARK ${ }^{1^{*}} \odot$, \\ THI-MY LE HUYNH ${ }^{2}$, SOOK SHIN ${ }^{3}$, WOO KYUNG JUNG ${ }^{3}$, \\ YONG HO PARK ${ }^{3 * *} \odot$ and HEE CHUN CHUNG ${ }^{1 *} \odot$
}

\footnotetext{
${ }^{1}$ Department of Veterinary Medicine Virology Lab, College of Veterinary Medicine and Research Institute for Veterinary Science, Seoul National University GwanAk-Ro 1, GwanAk-Gu, Seoul 151-742, Korea

${ }^{2}$ Department of Veterinary Microbiology and Infectious Diseases, Faculty of Veterinary Medicine, Vietnam National University of Agriculture, Hanoi, Vietnam

${ }^{3}$ Department of Veterinary Microbiology, College of Veterinary Medicine and Research Institute for Veterinary Science, Seoul National University, Seoul 151-742, Republic of Korea
}

Received: 1 August 2020 - Accepted: 7 January 2021

Published online: 15 March 2021

\begin{abstract}
Porcine epidemic diarrhoea virus (PEDV) is one of the major pathogens causing acute enteritis, which is characterised by vomiting and watery diarrhoea and commonly leads to high rates of mortality and morbidity in suckling piglets. Chitosan has been regarded as a promising natural disinfectant. In this study, the disinfectant effect and mammalian-cell toxicity of chitosan were evaluated against PEDV using Vero cells. A $0.01 \%$ solution of chitosan was determined to be an effective disinfectant. In addition, no evidence of toxicity was observed during the cell toxicity test; on the contrary, chitosan promoted cell proliferation. In conclusion, chitosan is a promising candidate for an effective and safe disinfectant against PEDV as well as other coronaviruses.
\end{abstract}

\section{KEYWORDS}

chitosan, coronavirus, PEDV, disinfectant

\section{INTRODUCTION}

Porcine epidemic diarrhoea virus (PEDV) is one of the major pathogens causing acute enteritis, which is characterised by vomiting and watery diarrhoea and commonly leads to high rates of mortality and morbidity in suckling piglets (Li et al., 2012). In the late 2010s, new and highly pathogenic strains, designated as G2 strains and having genetic features distinct from those of the old strains (G1 strains), were reported in China. These new strains were pathologically more critical than the classic strains, resulting in morbidity rates of 80 $100 \%$ and mortality rates of $50-100 \%$ in infected suckling piglets (Cima, 2014; Vlasova et al., 2014). In May 2013, these G2 strains moved from China to the USA and rapidly spread across the country, massively impacting the swine industry; they affected more than 4,000 farms, accounting for the death of more than 7 million piglets within the year (Cima, 2014; Vlasova et al., 2014). Subsequently, these strains became pandemic (Lee et al., 2016; Guo et al., 2019).

Chitosan (formed by the deacetylation of chitin), which is extracted from shellfish such as crabs and shrimp, is a non-toxic and hydrophilic polysaccharide (Tomihata and Ikada, 1997). It has been widely used in the medical and bioengineering fields for wound healing, drug delivery and cell culture, and has a variety of advantageous features, including low 
toxicity, low cost, antimicrobial activity, biodegradability, and biocompatibility (Khor and Lim, 2003). Among these advantages, its non-toxic nature and antimicrobial activity make it a promising substance for use as a less harmful disinfectant. Thus, we evaluated the disinfectant effect and safety of chitosan using a human coronavirus surrogate and Vero cells to identify its potential as a disinfectant for coronavirus.

\section{MATERIALS AND METHODS}

For evaluating the disinfectant effect of chitosan, a 1\% chitosan solution was prepared by dissolving chitosan (deacetylate level: 95\%, molecular weight: $30 \mathrm{kDa}$ ) (Nguyen et al., 2013) in 1\% acetic acid solution from NoAH Biotech (Korea). The PEDV strain DR-13 was cultivated in Vero cells using the method described by Song et al. (2003). Strain DR-13 is a PEDV strain attenuated through serial passages resulting in a 51-nucleotide deletion in the ORF3 gene (Park et al., 2008), and it is being used for a PED oral vaccine (DR13 $10^{5} \mathrm{TCID}_{50} / \mathrm{mL}$ ) commercialised in 2003 by Green Cross Vet. Prod. (South Korea). Virus titration was carried out using a 96-well microplate with Vero cells. Virus cultures were serially diluted 10 -fold with the virus replication medium containing trypsin. Confluent Vero cells of the microplate were washed three times with PBS and inoculated at $0.1 \mathrm{~mL}$ per well into five wells. Following adsorption for $1 \mathrm{~h}$ at $37^{\circ} \mathrm{C}$, the inocula were removed, and the cells were washed three times with PBS. Subsequently, $0.1 \mathrm{~mL}$ of fresh virus replication medium containing trypsin was transferred into each well, and the cells were further incubated for 5 days at $37{ }^{\circ} \mathrm{C}$. Fifty per cent tissue culture infective doses $\left(\mathrm{TCID}_{50}\right)$ were expressed as the reciprocal of the highest virus dilution showing cytopathic effect (CPE) (Kusanagi et al., 1992). Finally, viral inocula were adjusted to $10^{6.9}$ $\mathrm{TCID}_{50} / \mathrm{mL}$ with PBS.

The disinfection test was performed separately under two different conditions: hard water $\left(0.305 \mathrm{~g} \mathrm{CaCl}_{2}\right.$ and $0.139 \mathrm{~g}$ $\mathrm{MgCl}_{2} \cdot 6 \mathrm{H}_{2} \mathrm{O}$ per $1 \mathrm{~L}$ distilled water) and organic water ( $5 \%$ fetal bovine serum in hard water). The original solution ( $1 \%$ chitosan) was diluted 100 - to 800 -fold in both hard and organic water. Each diluent $(1 \mathrm{~mL})$ was mixed with $1 \mathrm{~mL}$ of virus solution $\left(10^{6.9} \mathrm{TCID}_{50} / \mathrm{mL}\right)$ or with $1 \mathrm{~mL}$ of non-viral culture medium for the toxicity control. Hard or organic water $(1 \mathrm{~mL})$ was mixed with $1 \mathrm{~mL}$ of the virus solution as the negative control. The mixtures and the negative controls (hard or organic water) were incubated at room temperature for $30 \mathrm{~min}$. Subsequently, viral titrations of each mixture and the negative controls were performed using the method

Table 1. Antiviral activity of chitosan on porcine epidemic diarrhoea virus

\begin{tabular}{|c|c|c|c|c|c|c|}
\hline \multirow[b]{2}{*}{ Treatment condition } & \multicolumn{5}{|c|}{ Experiment $\left(\log \mathrm{TCID}_{50} / \mathrm{mL}\right)$} & \multirow[b]{2}{*}{ Effective dilution factor } \\
\hline & Dilution & First & Second & Third & Median & \\
\hline \multirow[t]{9}{*}{ Hard water } & $1: 100$ & 0.9 & 0.9 & 1.1 & 0.9 & \multirow[t]{9}{*}{$1: 150$} \\
\hline & $1: 150$ & 1.5 & 1.5 & 1.5 & 1.5 & \\
\hline & $1: 200$ & 2.9 & 3.1 & 3.1 & 3.1 & \\
\hline & $1: 250$ & 3.3 & 3.3 & 3.5 & 3.3 & \\
\hline & $1: 300$ & 3.7 & 3.9 & 3.9 & 3.9 & \\
\hline & $1: 400$ & 4.3 & 4.3 & 4.3 & 4.3 & \\
\hline & $1: 500$ & 5.5 & 5.5 & 5.5 & 5.5 & \\
\hline & $1: 600$ & 5.7 & 5.9 & 5.7 & 5.7 & \\
\hline & $1: 800$ & 6.1 & 6.1 & 6.1 & 6.1 & \\
\hline \multirow[t]{9}{*}{ Organic water } & $1: 100$ & 2.3 & 2.1 & 2.1 & 2.1 & \multirow[t]{9}{*}{$1: 100$} \\
\hline & $1: 150$ & 2.9 & 3.1 & 3.1 & 3.1 & \\
\hline & $1: 200$ & 3.9 & 3.9 & 3.9 & 3.9 & \\
\hline & $1: 250$ & 4.3 & 4.5 & 4.5 & 4.5 & \\
\hline & $1: 300$ & 4.9 & 5.1 & 5.1 & 5.1 & \\
\hline & $1: 400$ & 5.9 & 5.9 & 5.9 & 5.9 & \\
\hline & $1: 500$ & 6.1 & 6.1 & 6.1 & 6.1 & \\
\hline & $1: 600$ & 6.3 & 6.3 & 6.3 & 6.3 & \\
\hline & $1: 800$ & 6.5 & 6.5 & 6.5 & 6.5 & \\
\hline Negative control & - & 6.7 & 6.7 & 6.9 & 6.7 & - \\
\hline \multirow[t]{9}{*}{ Toxicity control } & $1: 100$ & $\mathrm{NC}^{\mathrm{a}}$ & NC & NC & - & \multirow[t]{9}{*}{-} \\
\hline & $1: 150$ & $\mathrm{NC}$ & $\mathrm{NC}$ & NC & - & \\
\hline & $1: 200$ & $\mathrm{NC}$ & $\mathrm{NC}$ & $\mathrm{NC}$ & - & \\
\hline & $1: 250$ & $\mathrm{NC}$ & $\mathrm{NC}$ & $\mathrm{NC}$ & - & \\
\hline & $1: 300$ & $\mathrm{NC}$ & NC & NC & - & \\
\hline & $1: 400$ & $\mathrm{NC}$ & $\mathrm{NC}$ & NC & - & \\
\hline & $1: 500$ & $\mathrm{NC}$ & NC & NC & - & \\
\hline & $1: 600$ & $\mathrm{NC}$ & $\mathrm{NC}$ & $\mathrm{NC}$ & - & \\
\hline & $1: 800$ & $\mathrm{NC}$ & NC & $\mathrm{NC}$ & - & \\
\hline
\end{tabular}

NC: No cytopathic effect $(\mathrm{NC}<0.5)$. 
described above. Each sample was tested in three replicates. A maximum dilution factor, in which the virus titre was reduced by at least $4 \log _{10}$, was determined to be an effective dilution factor (Jimenez and Chiang, 2006; de Oliveira et al., 2011). Additionally, indirect immunofluorescence assays (IFA) were performed to more precisely detect the presence of the virus. Before inoculation of the mixture, all procedures were performed in the same manner as described above. IFA was carried out using the PEDV IFA kit (MEDIAN Diagnostics, South Korea) $24 \mathrm{~h}$ after inoculation.

For the safety test, the $1 \%$ chitosan solution was diluted 100- to 800 -fold in hard water. Hard water without chitosan was used for the negative controls. A $0.5-\mathrm{mL}$ aliquot of each diluent and the negative control was inoculated into $1.2 \times$ $10^{4}$ cells/well seeded in a 24 -well plate in which Vero cells were grown in a monolayer. Each sample was tested in three replicates. Cell morphology was observed after $24 \mathrm{~h}$.

To investigate the effect of chitosan on cell activity, a cell culture medium containing chitosan ( $1 \%$ chitosan, $1 \%$ acetic acid, $5 \%$ fetal bovine serum, penicillin 100 units $/ \mathrm{mL}$, streptomycin $100 \mu \mathrm{g} / \mathrm{mL}$, and amphotericin B $0.25 \mathrm{~g} / \mathrm{mL}$ in
DMEM) was prepared. The medium was diluted 2- to 800fold with the same solution without chitosan, which was also used for the negative control. Cell counting was performed using Countess ${ }^{\mathrm{TM}}$ Cell Counting kits with protocol (Invitrogen, USA) at 24, 48, 72, and $96 \mathrm{~h}$ after inoculation. Each sample was tested in duplicate. The cell counting data were analysed with Tukey's test using SPSS statistics 20 (IBM Corp., USA).

\section{RESULTS AND DISCUSSION}

In the test of disinfectant effect, some dilutions of chitosan were highly efficacious at reducing the viral titre. The effective dilutions under hard and organic water conditions were 150 -fold $(0.0067 \%$ chitosan) and 100 -fold $(0.01 \%$ chitosan), respectively (Table 1 ).

The disinfectant effect of chitosan may be affected by the presence of organic compounds, such as insoluble acid polysaccharides, in the medium, as chitosan binds to these substances (Chirkov, 2002), which possibly led to the
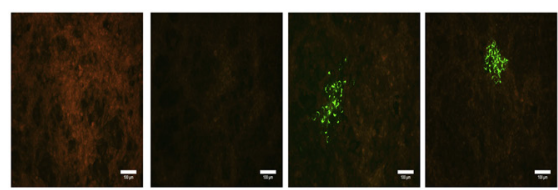

$1: 1$
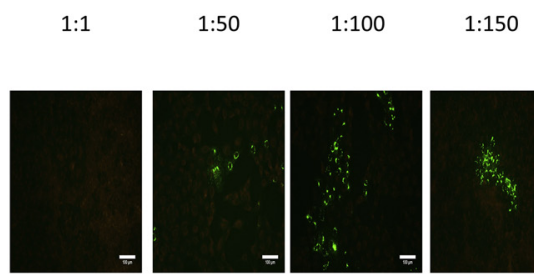
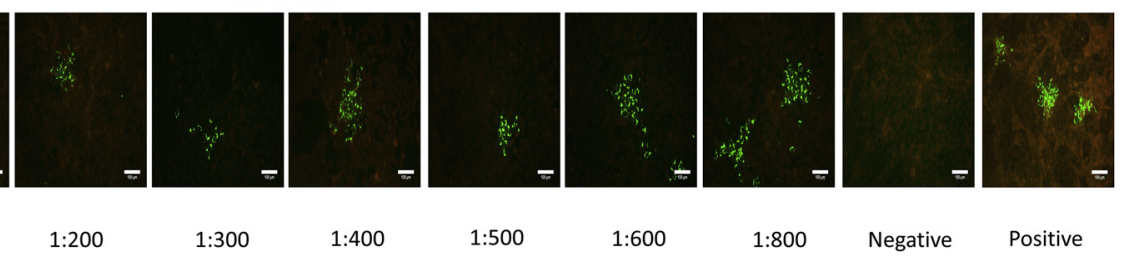

Organic water
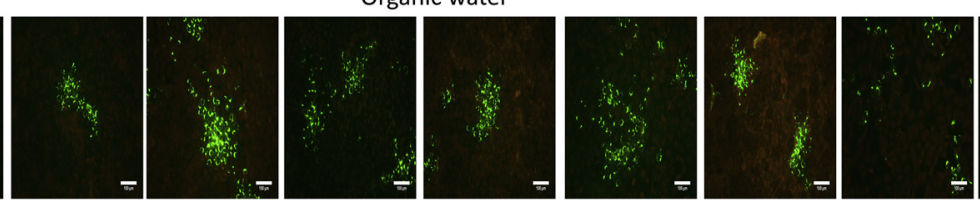

Negative

Positive
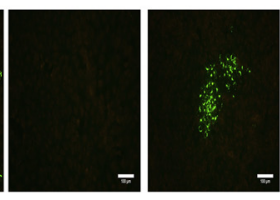

Fig. 1. Indirect immunofluorescence assay (IFA) of the disinfectant effect of chitosan. Under hard water conditions, no fluorescence was observed for the 1 -fold ( $1 \%$ chitosan) and 50 -fold $(0.02 \%$ chitosan) dilutions. Under organic water conditions, there was no evidence of fluorescence in the 1 -fold dilution

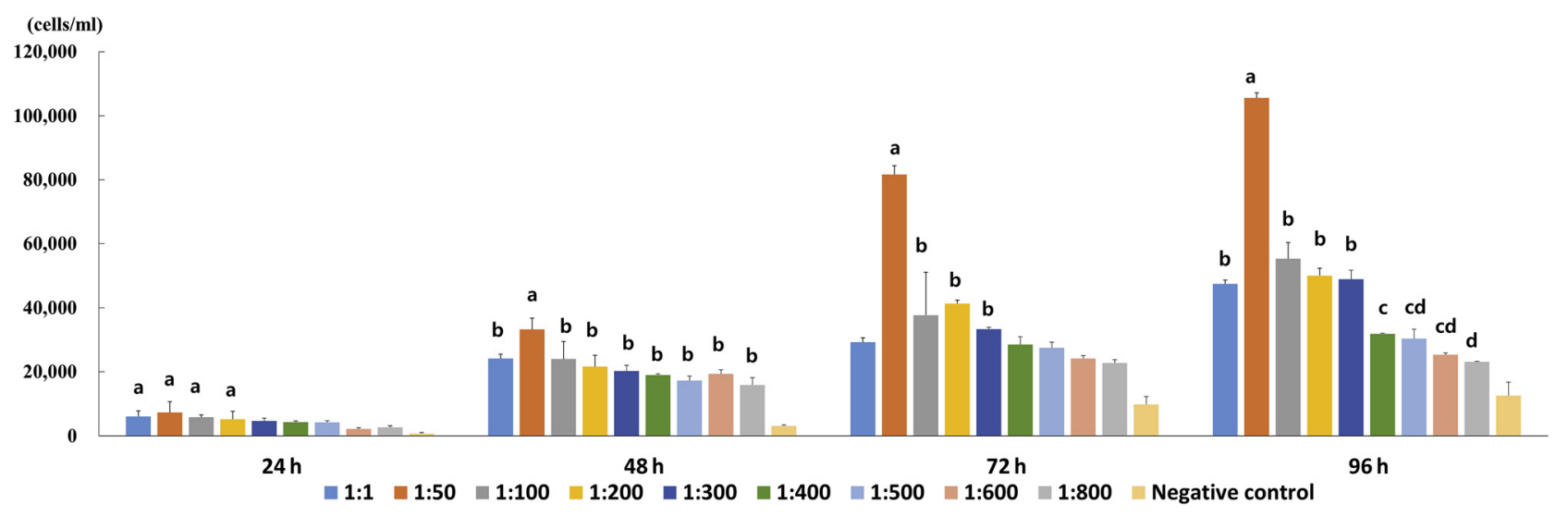

Fig. 2. Effect of chitosan on the proliferation of cultured Vero cells. Overall, chitosan promoted cell proliferation at all dilutions tested in this study, and the 50 -fold dilution ( $0.02 \%$ chitosan) showed the greatest effect. Letters a, b, c and d indicate chitosan dilution factors showing significant differences $(P<0.05)$ compared to the negative control (culture medium without chitosan). Different letters mean that there was a significant difference $(P<0.05)$ between two groups 


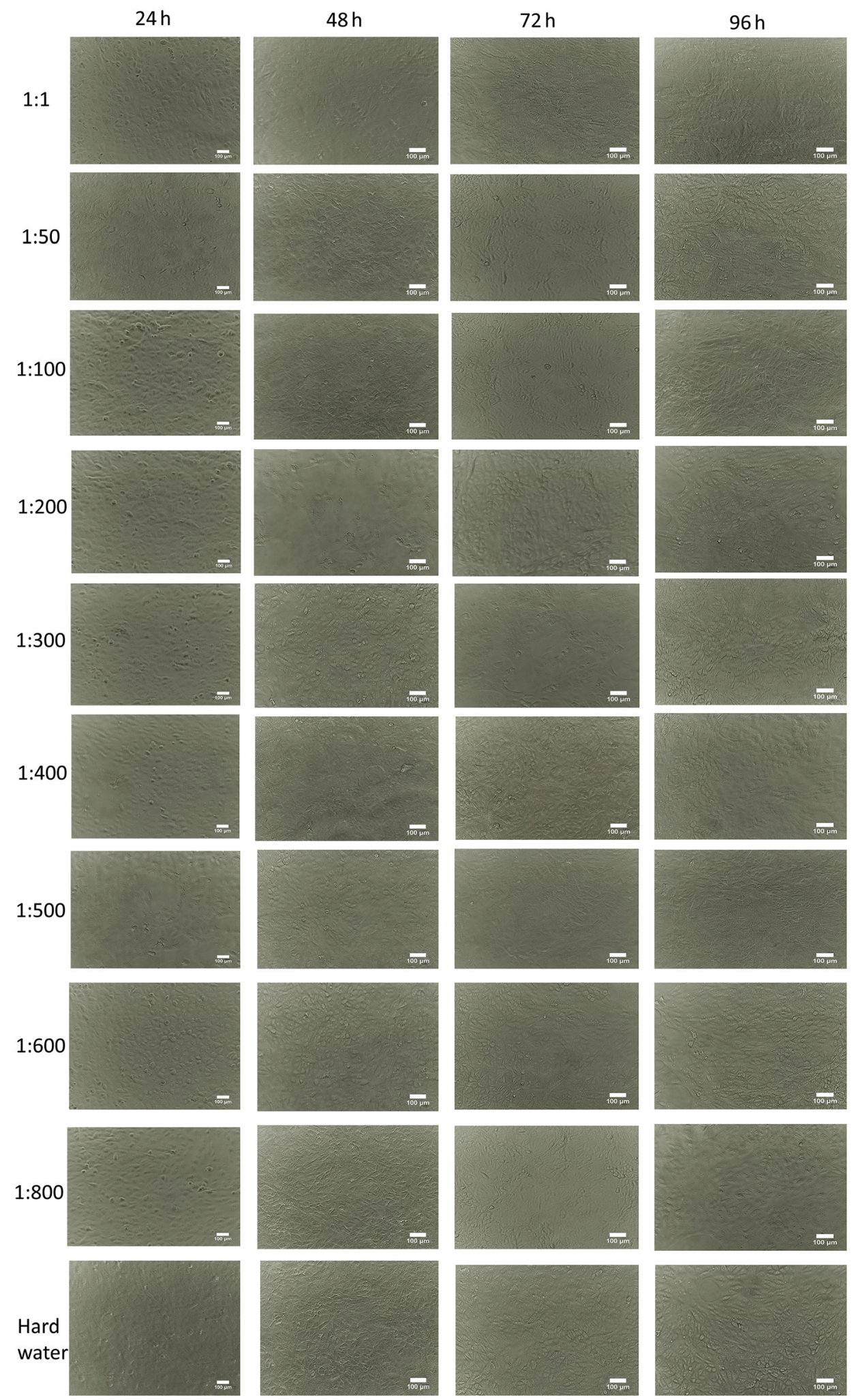

Fig. 3. Effect of chitosan on the proliferation of Vero cells in culture. No abnormal-appearing cells were observed for any of the chitosan dilutions during the experiment 
differences observed between the two conditions in this study. Previous studies have found that chitosan has antiviral activity on some phages as well as plant and animal viruses (Chirkov, 2002; Davis et al., 2012; Zheng et al., 2016). This activity is known to result from several mechanisms, including the neutralisation of virus infectivity by changing its membrane structure or integrity (Kochkina et al., 2000), blocking viral replication (Kochkina and Chirkov, 2000) and enhancing host immunity (Zheng et al., 2016). In this study, the cells were exposed to chitosan for only $1 \mathrm{~h}$ during virus adsorption, thus there was less possibility of chitosan affecting viral replication. It was also difficult to assess the immunological effect of chitosan because the test was performed on Vero cells, which are not immune cells in vitro. Therefore, we believe that the disinfectant effect of chitosan in this study was derived from its virus-neutralising effect.

The disinfectant effect of chitosan was strongly supported by the results of the IFA assays (Fig. 1). Under hard water conditions, no fluorescence was seen for the 1 -fold ( $1 \%$ chitosan) and 50 -fold ( $0.02 \%$ chitosan) dilutions. Under organic water conditions, no fluorescence was found for the 1 -fold dilution. Therefore, this new disinfectant completely eliminated the virus at these degrees of dilution. Overall, the undiluted solution ( $1 \%$ chitosan) was the most effective. Nevertheless, considering both efficacy and economic aspects, a $0.01 \%$ chitosan solution is a reasonable concentration for commercial products.

In the safety test, no abnormal cell features were observed. It is noteworthy that all the chitosan dilutions enhanced cell proliferation (Figs 2 and 3), and the 50-fold dilution $(0.02 \%$ chitosan $)$ resulted in the greatest effect (Fig. 2).

As a result, chitosan is expected to provide significant benefits to researchers using this cell line. However, chitosan is known to positively or negatively affect cell proliferation, depending on its concentration and molecular and biochemical features. According to Howling et al. (2001), chitosan enhanced the proliferation of human dermal fibroblasts but inhibited that of immortalised human keratinocytes. Thus, further studies on other cell lines are required.

Although it is often thought that disinfectants have broad-spectrum efficacy, certain substances can be effective or ineffective against specific pathogens, thus a specific evaluation is necessary (McDonnell and Russell, 1999). This study is the first to confirm the disinfectant effect of chitosan on PEDV. Coronaviruses infect a wide range of host species, including reptiles, birds, and mammals, and can cause respiratory or intestinal disease in most hosts. Moreover, the recently emerged coronaviruses causing Severe Acute Respiratory Syndrome (SARS), Middle East Respiratory Syndrome (MERS), and SARS-2, which originated from bats, pose a serious threat to human health (Li et al., 2020). Generally, it has been known that various types of coronavirus resemble each other in morphology and chemical structure (Tyrrell et al., 1996). Thus, it is also expected that chitosan is highly likely to exert a disinfectant effect on other coronavirus types including human coronaviruses when considering its virus neutralisation mechanism. However, further investigations on other coronaviruses are required to confirm our hypothesis.

Chitosan has been widely used as a popular biopolymer ingredient in various industries due to its low cost and ease of production (Khor and Lim, 2003; Jiang et al., 2014). Thus, chitosan is considered to be suitable for use as a commercial disinfectant. Moreover, there is an increasing need for less harmful disinfectants against coronavirus as Coronavirus Disease 2019 (COVID-19) has caused a global outbreak. So far, various chemical disinfectants have been commonly used for disinfection in human beings as well as companion animals and livestock, but the toxicity of these chemical disinfectants in mammals may cause problems (Chang et al., 2020). In fact, recent data collected by the Centers for Disease Control and Prevention (CDC) investigators highlight this risk by showing a $36 \%$ increase in poisoning accidents in the USA from 2019 to 2020 following the COVID19 outbreak (Chang et al., 2020). The non-toxicity of chitosan has been widely accepted (Khor and Lim, 2003; Jiang et al., 2014), and this feature was also confirmed in this study.

Chitosan appears to be a promising non-toxic and economical ingredient for disinfectants to be used for preventing coronavirus transmission. This study focused on the effectiveness of chitosan under liquid conditions; however, in many situations disinfectants are also used on hard surfaces, thus further studies are required to validate the efficacy of chitosan in such situations.

\section{ACKNOWLEDGEMENTS}

The authors would like to thank Jung Ah Kim and Eun Ok Kim for excellent technical assistance. This work was supported by the Korea Science and Engineering Foundation (KOSEF) grant funded by the government of Korea (No. 2020R1I1A1A01054539).

\section{REFERENCES}

Chang, A., Schnall, A. H., Law, R., Bronstein, A. C., Marraffa, J. M., Spiller, H. A., Hays, H. L., Funk, A. R., Mercurio-Zappala, M., Calello, D. P., Aleguas, A., Borys, D. J., Boehmer, T. and Svendsen, E. (2020): Cleaning and Disinfectant Chemical Exposures and Temporal Associations with COVID-19 - National Poison Data System, United States, January 1, 2020-March 31, 2020. Morbidity and Mortality Weekly Report (MMWR), Vol. 69. Centers for Disease Control and Prevention, USA.

Chirkov, S. (2002): The antiviral activity of chitosan. Appl. Biochem. Microbiol. 38, 1-8.

Cima, G. (2014): PED virus reinfecting US herds. Virus estimated to have killed 7 million-plus pigs. J. Am. Vet. Med. Assoc. 245, 166-167.

Davis, R., Zivanovic, S., D'Souza, D. H. and Davidson, P. M. (2012): Effectiveness of chitosan on the inactivation of enteric viral surrogates. Food Microbiol. 32, 57-62. 
de Oliveira, T. M. L., Rehfeld, I. S., Guedes, M. I. M. C., Ferreira, J. M. S., Kroon, E. G. and Lobato, Z. I. P. (2011): Susceptibility of Vaccinia virus to chemical disinfectants. Am. J. Trop. Med. Hyg. 85, 152-157.

Guo, J., Fang, L., Ye, X., Chen, J., Xu, S., Zhu, X. and Xiao, S. (2019): Evolutionary and genotypic analyses of global porcine epidemic diarrhea virus strains. Transbound. Emerg. Dis. 66, 111-118.

Howling, G. I., Dettmar, P. W., Goddard, P. A., Hampson, F. C., Dornish, M. and Wood, E. J. (2001): The effect of chitin and chitosan on the proliferation of human skin fibroblasts and keratinocytes in vitro. Biomaterials 22, 2959-2966.

Jiang, T., James, R., Kumbar, S. G. and Laurencin, C. T. (2014): Chitosan as a biomaterial: structure, properties, and applications in tissue engineering and drug delivery. In: Kum bar, S. G., Laurencin, C. and Deng, M. (eds) Natural and Synthetic Biomedical Polymers. Elsevier. pp. 91-113.

Jimenez, L. and Chiang, M. (2006): Virucidal activity of a quaternary ammonium compound disinfectant against feline calicivirus: a surrogate for norovirus. Am. J. Infect. Control 34, 269-273.

Khor, E. and Lim, L. Y. (2003): Implantable applications of chitin and chitosan. Biomaterials 24, 2339-2349.

Kochkina, Z. and Chirkov, S. (2000): Effect of chitosan derivatives on the reproduction of coliphages T2 and T7. Microbiology 69, 208-211.

Kochkina, Z., Surgucheva, N. and Chirkov, S. (2000): Inactivation of coliphages by chitosan derivatives. Microbiology 69, 212-216.

Kusanagi, K.-I., Kuwahara, H., Katoh, T., Nunoya, T., Ishikawa, Y., Samejima, T. and Tajima, M. (1992): Isolation and serial propagation of porcine epidemic diarrhea virus in cell cultures and partial characterization of the isolate. J. Vet. Med. Sci. 54, 313-318.

Lee, J., Chung, H., Nguyen, V., Moon, H., Kim, H. K., Park, S. and Park, B. (2016): Detection and phylogenetic analysis of porcine deltacoronavirus in Korean swine farms, 2015. Transbound. Emerg. Dis. 63, 248-252.
Li, J., Li, J. J., Xie, X., Cai, X., Huang, J., Tian, X. and Zhu, H. (2020): Game consumption and the 2019 novel coronavirus. The Lancet Infect. Dis. 20, 275-276.

Li, W., Li, H., Liu, Y., Pan, Y., Deng, F., Song, Y. and He, Q. (2012): New variants of porcine epidemic diarrhea virus, China, 2011. Emerg. Infect. Dis. 18, 1350-1353.

McDonnell, G. and Russell, A. D. (1999): Antiseptics and disinfectants: activity, action, and resistance. Clin. Microbiol. Rev. 12, 147-179.

Nguyen, M.-H., Hwang, I.-C. and Park, H.-J. (2013): Enhanced photoprotection for photo-labile compounds using doublelayer coated corn oil-nanoemulsions with chitosan and lignosulfonate. J. Photochem. Photobiol. B: Biol. 125, 194-201.

Park, S.-J., Moon, H.-J., Luo, Y., Kim, H.-K., Kim, E.-M., Yang, J.-S. and Park, B.-K. (2008): Cloning and further sequence analysis of the ORF3 gene of wild-and attenuated-type porcine epidemic diarrhea viruses. Virus Gene. 36, 95-104.

Song, D., Yang, J., Oh, J., Han, J. and Park, B. (2003): Differentiation of a Vero cell adapted porcine epidemic diarrhea virus from Korean field strains by restriction fragment length polymorphism analysis of ORF 3. Vaccine 21, 1833-1842.

Tomihata, K. and Ikada, Y. (1997): In vitro and in vivo degradation of films of chitin and its deacetylated derivatives. Biomaterials 18, 567-575.

Tyrrell, D. A. J., Myint, S. H. and Baron, S. (1996): Coronaviruses. In: Medical Microbiology. 4th edition. University of Texas Medical Branch at Galveston, Galveston, TX.

Vlasova, A. N., Marthaler, D., Wang, Q., Culhane, M. R., Rossow, K. D., Rovira, A. and Saif, L. J. (2014): Distinct characteristics and complex evolution of PEDV strains, North America, May 2013-February 2014. Emerg. Infect. Dis. 20, 1620-1628.

Zheng, M., Qu, D., Wang, H., Sun, Z., Liu, X., Chen, J. and Chen, Z. (2016): Intranasal administration of chitosan against influenza A (H7N9) virus infection in a mouse model. Sci. Rep. 6, 28729. 